\title{
Orbital lymphangioma: an analysis of 26 patients
}

\author{
Murat Tunç, Ehsan Sadri, Devron H Char
}

\begin{abstract}
Aim-To evaluate retrospective data on the clinical findings, histological features, radiological diagnosis, and management outcomes in orbital lymphangioma.

Methods-Data on 26 orbital lymphangioma patients managed over 16 years were re-evaluated. The computed tomograph and magnetic resonance scans and histological slides were reviewed. Parametric techniques were used to assess correlations among clinical, radiological, and histopathological factors.

Results-At presentation proptosis was present in $85 \%$, ptosis in $73 \%$, and restrictive eye movements in $46 \%$ of patients. The accuracy of the initial radiology interpretations was $77 \% .24$ cases required one or more surgeries. The mean follow up was 9.2 years (range $1-14$ years). $58 \%$ of patients developed recurrences. In cases that recurred, motility restriction was significantly more frequent at initial examination than cases without recurrence $(p<0.05)$. After therapy, $75 \%$ of patients were satisfied with their visual function and cosmetic appearance.

Conclusions-Conservative management of orbital lymphangioma with multiple partial resections may achieve satisfactory results.

(Br f Ophthalmol 1999;83:76-80)
\end{abstract}

Lymphangiomas are benign hamartomatous tumours usually diagnosed in early childhood..$^{1-6}$ About $20 \%$ of these tumours involve the orbit and ocular adnexa; they account for less than $2 \%$ of orbital biopsies. ${ }^{167}$

Clinically, lymphangiomas usually present with a slowly progressive proptosis, displacement of the globe, ptosis, and restriction of eye movements; rarely focal lesions may remain asymptomatic. ${ }^{568-10}$ Spontaneous intraorbital haemorrhage may cause acute proptosis, compressive optic neuropathy, and loss of the vision. ${ }^{1-3} 5^{8}$ In children who developed marked ptosis deprivation amblyopia may develop.

The nature of these hamartomas is uncertain, some are in continuity with the venous circulation; rarely, they can be associated with an arteriovenous malformation. ${ }^{21-14}$ Most do not have radiological evidence of a vascular connection. Several authors have questioned the validity of the term orbital lymphangioma and believe that all of these tumefactions are variants of venous malformations. ${ }^{211-14}$

Management of orbital and adnexal lymphangioma can be challenging. In symptomatic patients the infiltrative, diffuse nature of the lesion usually allows only a partial resection..$^{1-35}{ }^{15-17}$ In this study, we analysed clinical features, radiological findings, histopathological variables, and treatment results.

\section{Patients and methods}

Twenty six patients with classic orbital lymphangiomas that were managed at the Ocular Oncology Unit, University of California, San Francisco, between 1980 and 1996 were included in this study. All patients were evaluated and managed by one physician (DHC). We excluded patients if they had less than 1 year follow up or those with clinical or radiological evidence of either a venous or arteriovenous malformation in association with this tumour.

Retrospective data were collected from clinical charts and both radiology and pathology reports. We evaluated the clinical data for presenting symptoms, physical findings, treatment results, visual outcome, recurrence rates, and cosmetic satisfaction. Visual acuities were tested by Snellen chart or Allen cards. Quantitative visual acuities were not routinely measured in patients under 2 years old. Treatment modalities, patterns of recurrence, and disease characteristics were analysed.

We re-evaluated the pathology slides for presence or absence of dilated endothelial lined vascular channels, haemorrhage, lymphoid cells, and fibrosis. Radiology scans were categorised according to tumour location (intraconal, extraconal, or combined), and classified as to the focal or diffuse nature of the mass. A focal lesion was defined as a well localised tumour with distinct borders and a diffuse lesion was defined as an infiltrative lesion with ill defined borders. On computed tomograph (CT) or magnetic resonance imaging (MRI) both coronal and axial images were evaluated and most CT scans were performed after dye injection. The lymphangiomas were diagnosed with the appearance of saccular lesions, often in clusters, without evidence of venous connection or high inflow. We compared the initial radiological diagnosis with histology to determine the accuracy of the radiologists' readings.

There were two indications for surgery. Firstly, to prevent the possible visual damage by decreasing tumour pressure on visually vital structures. Secondly, to debulk a cosmetically unsightly orbit. Lesions were either totally or partially resected with standard or carbon dioxide laser assisted surgery. We used a bipolar wet field diathermy to minimise periocular damage and haemorrhage during standard surgery. Carbon dioxide laser was used in some cases to obliterate areas of either lymphangiomatous involvement or areas of extensive scarring and fibrosis. 
Table 1 Clinical and radiological features and outcome of treatment

\begin{tabular}{|c|c|c|c|c|c|c|c|c|c|}
\hline \multirow[b]{2}{*}{ No } & \multirow[b]{2}{*}{ Age } & \multirow[b]{2}{*}{ Initial VA } & \multirow[b]{2}{*}{ Imaging } & \multicolumn{3}{|l|}{ Radiological findings } & \multirow[b]{2}{*}{ Preoperative radiology } & \multirow[b]{2}{*}{ Recurrences ( $n$ ) } & \multirow[b]{2}{*}{ Final VA } \\
\hline & & & & Shape and location & $O E$ & $C C$ & & & \\
\hline 1 & $1 \mathrm{~m}$ & N/A & CT & Diffuse, combined & - & - & Pseudotumour/lymphangioma & 1 & $\mathrm{CF}$ \\
\hline 2 & $2 \mathrm{~m}$ & $\mathrm{~N} / \mathrm{A}$ & $\mathrm{CT}$ & Diffuse, combined & - & - & Lymphangioma/haemangioma & 0 & $20 / 20$ \\
\hline 3 & $6 \mathrm{~m}$ & N/A & & & & & & 1 & $20 / 20$ \\
\hline 4 & $6 \mathrm{~m}$ & N/A & & & & & & 0 & $20 / 20$ \\
\hline 5 & $6 \mathrm{~m}$ & N/A & $\mathrm{CT}$ & Focal, combined & - & - & Haemangioma & 2 & $20 / 200$ \\
\hline 6 & $6 \mathrm{~m}$ & $\mathrm{~N} / \mathrm{A}$ & $\mathrm{CT}$ & Diffuse, combined & - & - & Haemangioma & 1 & $20 / 70$ \\
\hline 7 & $2 \mathrm{y}$ & N/A & & & & & & 3 & HM \\
\hline 8 & $2 \mathrm{y}$ & $\mathrm{N} / \mathrm{A}$ & MR & Diffuse, combined & - & - & Lymphangioma & 0 & $20 / 30$ \\
\hline 9 & $2 \mathrm{y}$ & NA & $\mathrm{CT}$ & Diffuse, extraconal & - & - & Lymphangioma/haemangioma & 0 & $20 / 20$ \\
\hline 10 & $2 \mathrm{y}$ & N/A & $\mathrm{CT}$ & Diffuse, extraconal & - & - & Lymphangioma & 0 & $20 / 20$ \\
\hline 11 & $3 \mathrm{y}$ & $20 / 20$ & CT & Diffuse, extraconal & - & - & Lymphangioma & 1 & $20 / 20$ \\
\hline 12 & $4 \mathrm{y}$ & $20 / 20$ & $\mathrm{CT} / \mathrm{MR}$ & Diffuse, combined & - & - & Lymphangioma, rhabdomyosarcoma & 1 & $20 / 20$ \\
\hline 13 & $4 \mathrm{y}$ & HM & $\mathrm{CT} / \mathrm{MR}$ & Diffuse, combined & + & + & Lymphangioma & 3 & $\star$ \\
\hline 14 & $5 \mathrm{y}$ & $20 / 50$ & CT & Diffuse, extraconal & - & - & Lymphangioma, rhabdomyosarcoma & 1 & $20 / 50$ \\
\hline 15 & $5 \mathrm{y}$ & $20 / 20$ & $\mathrm{CT} / \mathrm{MR}$ & Diffuse, combined & - & + & Lymphangioma & 3 & $20 / 20$ \\
\hline 16 & $5 \mathrm{y}$ & $20 / 50$ & CT/US & Diffuse, combined & + & - & Haemangioma & 0 & $20 / 50$ \\
\hline 17 & $5 \mathrm{y}$ & $20 / 25$ & MR & Diffuse, extraconal & - & + & Lymphangioma & 3 & $20 / 20$ \\
\hline 18 & $6 \mathrm{y}$ & $20 / 25$ & MR & Diffuse, combined & - & - & Lymphangioma & 0 & $20 / 20$ \\
\hline 19 & $8 \mathrm{y}$ & $20 / 20$ & $\mathrm{CT} / \mathrm{US}$ & Diffuse, combined & + & - & Haemangioma & 0 & $20 / 20$ \\
\hline 20 & $10 \mathrm{y}$ & $20 / 20$ & $\mathrm{CT}$ & Focal, combined & - & - & Lymphangioma & 0 & $20 / 20$ \\
\hline 21 & $12 \mathrm{y}$ & $20 / 20$ & CT/MR/US & Diffuse, combined & + & + & Lymphangioma & 1 & $20 / 20$ \\
\hline 22 & $13 \mathrm{y}$ & $20 / 30$ & $\mathrm{CT} / \mathrm{MR}$ & Focal, intraconal & - & - & Lymphangioma, lymphoma & 1 & $20 / 20$ \\
\hline 23 & $14 \mathrm{y}$ & $20 / 200$ & $\mathrm{CT} / \mathrm{MR} / \mathrm{US}$ & Diffuse, combined & - & - & Haemangioma & 3 & $20 / 25$ \\
\hline 24 & $16 \mathrm{y}$ & $20 / 60$ & & & & & & 1 & $20 / 40$ \\
\hline 25 & $48 \mathrm{y}$ & $20 / 25$ & $\mathrm{CT}$ & Diffuse, combined & - & - & Lymphangioma & 0 & $20 / 20$ \\
\hline 26 & $74 \mathrm{y}$ & $20 / 30$ & $\mathrm{CT} / \mathrm{MR}$ & Diffuse, combined & - & - & Lymphangioma & 0 & $20 / 20$ \\
\hline
\end{tabular}

$\mathrm{m}=$ months, $\mathrm{y}=$ years $\mathrm{CT}=$ computed tomography; $\mathrm{MR}=$ magnetic resonance imaging; $\mathrm{US}=$ ultrasound; $\mathrm{OE}=$ orbital enlargement; $\mathrm{CC}=$ chocolate cysts.

We evaluated the recurrence rates and patterns of growth after therapy. We arbitrarily defined a non-recurrence if there were no tumour related symptoms after treatment, even if the primary lesion was only partially resected. Recurrent cases were analysed to determine possible correlations with clinical, radiological, and histological findings; parametric methods were used for this analysis.

Cosmetic outcome was evaluated at the last follow up examination. We interviewed patients in 1997 to obtain post treatment satisfaction. These interviews were performed on the phone, with a written script, including items on visual functioning and cosmetic satisfaction. These items were modified from previous visual functioning questionnaires published elsewhere. ${ }^{18}$ We asked about self perception of the cosmetic appearance and treatment or disease related functional problems in everyday activities.

\section{Results}

CLINICAL FEATURES

Ten $(38 \%)$ patients were under 2 years old at the initial diagnosis; five of these cases were diagnosed during infancy ( $<6$ months old). Most patients developed symptoms in the first $(77 \%)$ or second decade $(15 \%)$ of life. Two lymphangiomas were diagnosed during adult life, at 48 and 64 years old, respectively. Twenty $(77 \%)$ patients were female and six $(33 \%)$ were male. Twenty two patients were white and four were Asian.

The right orbit was involved in 17 patients. Twenty $(77 \%)$ patients presented with only an orbital lesion; the others had either orbital and eyelid involvement or a mass of the orbit and conjunctiva. At the initial examination 22 (85\%) patients presented with proptosis; in 12 of these cases there was a proximate history of either an upper respiratory system infection or orbital trauma. Ten patients had chronic periocular pain. Five patients had mild conjunctival chemosis. Ptosis was noted at presentation in $19(73 \%)$ cases. At the initial examination $12(46 \%)$ patients had restriction of eye movements; four had hypotropia and esotropia; four had only esotropia; three had only hypotropia and one had exotropia. Diplopia was described by only two patients.

Quantitative visual acuities were measured in 16 patients over 2 years old. The best visual acuity was $\geqslant 20 / 30$ in 11 , between $20 / 40$ and $20 / 100$ in three, and $\$ 20 / 200$ in two cases. Amblyopia was responsible for decreased vision in three cases with visual acuities $<20 / 40$. At presentation two patients had optic disc pallor. One (patient 4) resolved with a $20 / 25$ vision after surgical treatment, while the other (patient 7) remained at hand movements (HM) vision. The visual status of the patients is summarised in Table 1.

\section{ORBITAL IMAGING FINDINGS}

We reviewed 33 radiological studies from 22 patients; $19 \mathrm{CT}, 10 \mathrm{MRI}$, and four ultrasound scans. We categorised the lesions on the basis of CT and MRI data into three locations, extraconal, intraconal, and combined (Table 1). In four patients the lesion was restricted to the extraconal region of the orbit. Only two patients had an isolated intraconal lesion. The remaining $16(73 \%)$ had diffuse lymphangiomas that involved both the extraconal and intraconal spaces. We further analysed the radiological appearance of the lesion as either focal or diffuse. On basis of CT and MRI three patients had a focal lesion while the remaining $19(86 \%)$ had diffuse orbital lymphangiomas. In 16 cases, the lesion occupied less than $25 \%$ of the orbital volume; the remaining lesions exceeded that volume. In four patients the entire bony orbit was enlarged. In three cases, extraorbital lymphangiomas were noted involving the maxillary sinus and temporalis muscle. None of the orbital scans showed a definite 
Table 2 Histopathological findings

\begin{tabular}{|c|c|c|c|c|c|}
\hline No & CVS & $H$ & $L C$ & $F$ & Others \\
\hline 1 & Yes & Yes & Yes & Yes & \\
\hline 2 & Yes & No & Yes & Yes & \\
\hline 3 & N/A & & & & \\
\hline 4 & No & No & Yes & No & Small sized vascular channels filled with eosinophilic material \\
\hline 5 & Yes & Yes & Yes & No & $\begin{array}{l}\text { Vascular channels are surrounded by thin layer of connective tissue } \\
\text { and irregular single layer endothelium }\end{array}$ \\
\hline 6 & Yes & Yes & Yes & Yes & $\begin{array}{l}\text { Irregular cystic spaces with flattened single layer endothelium and } \\
\text { subendothelial lymphoid aggregates }\end{array}$ \\
\hline 7 & N/A & & & & \\
\hline 8 & Yes & No & Yes & Yes & Irregular single layer endothelium with degenerated muscle cells \\
\hline 9 & Yes & Yes & Yes & Yes & $\begin{array}{l}\text { Varying size thin walled vascular channels partially covered by flat } \\
\text { endothelium }\end{array}$ \\
\hline 10 & Yes & Yes & Yes & Yes & $\begin{array}{l}\text { Large vascular channels lined by flattened endothelium with } \\
\text { degenerated muscle cells }\end{array}$ \\
\hline 11 & No & No & Yes & No & Single vascular dilated vascular space with partial endothelial lining \\
\hline 12 & Yes & Yes & Yes & No & Various sized vascular channels with intact flattened endothelium \\
\hline 13 & Yes & Yes & Yes & Yes & $\begin{array}{l}\text { Dilated irregular channels with flat single layer endothelium and } \\
\text { subendothelial lymphoid aggregates }\end{array}$ \\
\hline 14 & Yes & Yes & Yes & Yes & Irregular vascular channels with flattened single layer endothelium \\
\hline 15 & Yes & Yes & Yes & No & \\
\hline 16 & Yes & Yes & Yes & Yes & $\begin{array}{l}\text { Large irregular shaped cystic spaces lined by single layer } \\
\text { endothelium and subendothelial lymphatics }\end{array}$ \\
\hline 17 & Yes & Yes & Yes & Yes & $\begin{array}{l}\text { Dilated vascular channels partially covered by single layer } \\
\text { endothelium }\end{array}$ \\
\hline 18 & N/A & & & & \\
\hline 19 & Yes & Yes & Yes & No & $\begin{array}{l}\text { Dilated vascular spaces partly lined with flattened single layer } \\
\text { endothelium }\end{array}$ \\
\hline 20 & N/A & & & & \\
\hline 21 & Yes & Yes & Yes & Yes & $\begin{array}{l}\text { Vascular channels lined with single layer endothelium. No } \\
\text { endothelial layer in some areas }\end{array}$ \\
\hline 22 & Yes & Yes & Yes & Yes & $\begin{array}{l}\text { Single layer flattened endothelium with subendothelial lymphoid } \\
\text { aggregates }\end{array}$ \\
\hline 23 & N/A & & & & \\
\hline 24 & No & No & Yes & No & $\begin{array}{l}\text { Small sized vascular channels partly lined with single layer } \\
\text { endothelium }\end{array}$ \\
\hline 25 & Yes & Yes & Yes & Yes & $\begin{array}{l}\text { Single layered flattened endothelium with subendothelial lymphoid } \\
\text { aggregates }\end{array}$ \\
\hline 26 & No & Yes & Yes & Yes & Multiple vascular channels with thin stroma \\
\hline
\end{tabular}

CVS $=$ cystic vascular spaces $\mathrm{H}=$ intralesional haemorrhage $; \mathrm{LC}=$ lymphoid cells $; \mathrm{F}=$ fibrosis .

vascular connection on high resolution MRI or CT after dye injection.

The diagnostic accuracy of the imaging studies was assessed by comparing the initial radiology reports and histopathology. Lymphangiomas were misdiagnosed as orbital haemangiomas in five cases by a radiologist; in these five cases the initial radiological examination was a CT scan. Three radiology reports included haemangioma versus lymphangioma, two rhabdomyosarcoma versus lymphangioma, one lymphoma versus lymphangioma, and one pseudotumour versus lymphangioma in differential diagnosis. In only 10 cases did preoperative radiology reports correctly diagnose orbital lymphangioma. If all reports that included lymphangioma in differential diagnosis were considered, the accuracy was $77 \%$.

PATHOLOGICAL FINDINGS

We re-evaluated the histopathology slides in 21 patients. These findings are summarised in Table 2. In five cases slides were no longer accessible. None of the lesions was encapsulated. Seventeen specimens showed cystic vascular spaces filled with a proteinaceous, eosinophilic material. In all cases the vascular spaces were lined with a single layer flattened endothelium. In eight cases this single endothelial layer was partial and irregular. Haemorrhage was noted in 16 of 21 cases. All specimens demonstrated both lymphocytes and lymphoid aggregates. In five cases these lymphoid aggregates formed subendothelial follicular structures. Fibrosis was noted in 14 specimens. In 10 cases there was a mixture of intrinsic vessels, and these intrinsic vessels were slightly more prominent in extraconal cases. We did not discern a pattern of either dystrophic vessels or lymphoid infiltrates that correlated with any clinical factors or outcome.

SURGICAL TREATMENT

Two types of surgical management were attempted; a total resection and debulking. Two patients were minimally symptomatic and were followed without any treatment.

The mean follow up after initial surgery was 9.2 years (range $1-14$ years). In 10 of 24 patients there was no recurrence, nine of these had a partial surgical resection and one patient had a total resection. The mean age at presentation was 5.5 years old in non-recurrent cases. None of these 10 patients have had any subsequent eye surgeries related to this condition.

Symptomatic recurrences developed in 14 patients. The mean interval between treatment and the recurrence was 3.4 years. Eight of 14 cases did not recur again the second surgery. In seven of eight successful second procedures, partial resections were done; in one case the tumour was completely removed. Six (25\%) cases recurred a second time and five of these had a third recurrence. The mean interval between the third procedure and symptomatic recurrence was 11.5 months (1-22 months). One patient was exenterated, with a blind, painful eye and orbit, after several recurrences.

There was no significant difference between recurrent and non-recurrent cases regarding the presence or degree of the proptosis at the initial examination $(p>0.05)$. The mean value 
of proptosis was $3.6 \mathrm{~mm}$ in cases with recurrence and $3.7 \mathrm{~mm}$ in non-recurrent cases. At initial presentation in recurrent patients, restrictive eye movements were significantly more common than in the non-recurrent cases $(p=0.047)$. In four recurrent cases there was a definite chocolate cyst appearance at the initial MRI studies and all four recurred multiple times. There were no other significant correlation between other clinical, histological, and radiological findings and recurrence $(\mathrm{p}>0.05)$.

POST-TREATMENT FOLLOW UP

Visual acuity was $>20 / 30$ in $16(62 \%)$ patients after the treatment. Four (15\%) patients had vision between 20/40 and 20/70; all of these had amblyopia. In three cases the vision was $\leqslant 20 / 200$; amblyopia was the reason in two and optic atrophy in the other patient. One patient was exenterated.

Eighteen patients with proptosis felt they had improved significantly as a result of treatment. Similarly, there was a significant reduction of ptosis in 17 patients after therapy. Two patients with diplopia had a complete recovery after surgery. Eight of 10 patients with initial ocular pain had complete relief of pain and discomfort, while two continued to have periocular pain at least once a day.

Eighteen $(75 \%)$ of 24 treated patients were satisfied with their cosmetic appearance. These patients reported no functional or cosmetic problems with the involved eye and orbit. In six cases periocular cutaneous scarring was a cosmetic problem. None of the cases reported persistent diplopia, and other than one exenterated case, none reported difficulties in performing everyday activities.

\section{Discussion}

Orbital lymphangioma may produce a myriad of symptoms. In contrast with their benign histology, these tumours have a locally aggressive nature. Their radiological appearance may mimic other tumours and their histological features may overlap with orbital vascular anomalies. ${ }^{2} 451113141719$

In our series females outnumbered males; previous series also show a female predominance. ${ }^{15}{ }^{11-17} 19$ We noted no difference in recurrence rates between females and males. Most of our patients were white but lymphangiomas have been reported in all races..$^{1-35}$ Although right orbital involvement was more common in our series, there was no significant difference in other reports. ${ }^{1-3} 51119$

Lymphangiomas are hamartomatous malformations with a normal cell replication cycle. ${ }^{1-5} 11121920$ Some investigators believe that venous lymphatic shunts are important in the pathophysiology of these lesions since lymphatic channels develop in association with the venous plexus during the embryonic period. ${ }^{2}{ }^{12}$ Other authors believe that lymphangiomas are haemodynamically isolated vascular hamartomas. ${ }^{5114}$ The histological pattern of orbital lymphangioma is characteristic; however, overlapping factors with other orbital vascular abnormalities, and intriguing observations of venous connections in some lesions has led to a terminology debate. ${ }^{211-13}$ In our series we did not include those patients with radiologically or histologically demonstrable venous connections.

Most of our lesions had thin walled stroma; a single layer of flattened epithelium with occasional breaks in continuity, and lymphoid infiltration. Aggregates of lymphoid cells in the subendothelial space were present in five of our cases. $^{3511}$ In three quarters of our specimens there was haemorrhagic material in small cystic spaces. Reese and Howard ${ }^{9}$ demonstrated capillaries within lymphatic spaces that may explain the aetiology of these haemorrhages. ${ }^{9}$ As others have noted, we found fibrosis present in approximately half of our cases probably as a result of chronic recurrent haemorrhages. $^{591114}$ We did not find a specific histological feature that correlated with recurrence.

We evaluated the accuracy of radiological reports based on CT or MR scans. In the early portion of our study, we relied on CT imaging. MRI developments provided better anatomical demonstration of the cystic nature and haemorrhages in lymphangiomas. ${ }^{517} 1921$ These lesions did not enhance with gadolinium which supports the haemodynamically isolated nature of our orbital lymphangiomas. In our series, radiological diagnostic accuracy of MR was superior to CT; however, true diagnostic accuracy cannot be assessed in a long term retrospective series. The lack of ionising radiation, high resolution, and multiplanar capacities with MRI probably make it a superior imaging modality for lymphangiomas compared with CT. ${ }^{5171921}$ On the other hand, helical CT, which can be performed without anaesthesia in children, has a distinct advantage since $\mathrm{MR}$ in young children requires sedation. ${ }^{6}$ We did not use orbital venography; it is a difficult procedure in childhood and may result in secondary haemorrhage. ${ }^{22}$ Others have demonstrated the failure of lymphangiomas to opacify with venography. ${ }^{2}{ }^{12}$

We retrospectively reviewed correlation between radiological features and recurrences. Four patients with chocolate cysts developed multiple recurrences. No other radiological finding correlated with recurrence.

Early presentation of orbital lymphangioma may be associated with a greater risk for the development of amblyopia, strabismus, and compressive optic neuropathy. ${ }^{51011}$ In our series, all patients who had a final visual acuity $<20 / 40$ were under 6 years old at presentation with ptosis and/or strabismus. Earlier studies have not observed an association between the age at presentation and recurrence; in our series all patients who presented in the second decade had multiple recurrences. ${ }^{1-3} 5111219$ Our patients that recurred demonstrated restrictive eye movements on their initial examination more often than the non-recurrent cases; it is unclear whether this was a result of a more infiltrative process, recurrent haemorrhagic episodes, or both. We did not detect other positive correlations between clinical findings and recurrent disease. 
Management of orbital lymphangioma is difficult and surgery remains the treatment of choice. ${ }^{13511} 1215161923$ Carbon dioxide laser is a useful adjuvant in some cases. ${ }^{6}{ }^{15} \mathrm{~A}$ few patients have been treated with other modalities including irradiation or sclerosing agents but there are sparse data with those approaches. ${ }^{2425}$

In lymphangioma the main goal of the treatment is preservation of visual function and cosmesis. Our results show that multiple partial resections may be necessary to obtain good control of the lesion and satisfactory cosmetic results.

Presented in part at the American Society of Ophthalmic Plastic and Reconstructive Surgery Meeting in conjunction with 1997 Annual American Academy of Ophthalmology Meeting, San Francisco, October 1997.

1 Jones IS. Lymphangiomas of the ocular adnexa: analysis of 62 cases. Am $\mathcal{F}$ Ophthalmol 1961;51:481-509.

2 Wright JE. Orbital vascular anomalies. Trans Am Acad Ophthalmol Otol 1974;78:607-16.

3 Iliff WJ, Green WR. Orbital lymphangiomas. Ophthalmology 1979;86:914-29.

4 Mulliken JB, Glowacki J. Hemangiomas and vascular malformations in infants and children: a classification based on endothelial characteristics. Plast Reconstr Surg 1982;69:412-20.

5 Harris GJ, Sakol PJ, Bonavolonta G, et al. An analysis of thirty cases of orbital lymphangioma: pathophysiologic considerations and management recommendations. Ophthalmology 1990; 97:1583-92.

6 Char DH. Benign vascular tumors of childhood. In: Char DH. Clinical ocular oncology. 2nd ed. Philadelphia: Lippincott-Raven, 1997:295-300.

7 Brock ME, Smith RJH, Parey SE, et al. Lymphangioma. An otolaryngologic perspective. Int $\mathcal{F}$ Pediatr Otolaryngol 1987; 14:133-40

8 Dryden RM, Wulc AE, Day D. Eyelid ecchymosis and proptosis in lymphangioma. Am $\mathcal{F}$ Ophthalmol 1985;100:486-7.
9 Reese AB, Howard GM. Unusual manifestations of ocular Reese AB, Howard GM. Unusual manifestations of ocular lymphangioma

10 Enzenauer RW, Byers NT. Unequal refractive error and high astigmatism associated with orbital lymphangioma. Military Med 1993;158:429-31.

11 Graeb DA, Rootman J, Robertson WD, et al. Orbital ymphangiomas: clinical, radiologic and pathologic characteristics. Radiology 1990;175:417-21.

12 Wright JE, Sullivan TJ, Garner A, et al. Orbital venous anomalies. Ophthalmology 1997; 104:905-13.

13 Garrity JA. Orbital venous anomalies: a long standing dilemma. Ophthalmology 1997;104:903-4.

14 Rootman J, Hay E, Graeb D, et al. Orbital-adnexal lymphangiomas: a spectrum of hemodynamically isolated vascular hamartomas. Ophthalmology 1986;93:1558-70.

15 Kennerdell JS, Maroon JC, Garrity JA, et al. Surgical management of orbital lymphangioma with the carbon dioxide laser. Am f Ophthalmol 1986;102:308-14.

16 Saraux H, Laroche L, Josset P, et al. Lymphangioma of the orbit. F Fr Ophtalmol 1985;8:579-84.

17 Haik BG, Saint Louis L, Smith ME, et al. Magnetic resonance imaging of orbital lymphangiomas. Am 7 resonance imaging of orb

18 Steinberg EP, Tielsch JM, Schein OD et al. The VF-14. An index of functional impairment in patients with cataract. Arch Ophthalmol 1994; 112:630-8.

19 Kazim M, Kennerdell JS, Rothfus W, et al. Orbital lymphangioma: correlation of magnetic resonance images and intraoperative findings. Ophthalmology 1992;99:158894.

20 Font RL, Wheeler TM, Boniuk M. Intravascular papillary endothelial hyperplasia of the orbit and ocular adnexa: a report of five cases. Arch Ophthalmol 1983;101:1731-6.

21 Char DH, Sobel D, Kelly WM, et al. Magnetic resonance scanning in orbital tumor diagnosis. Ophthalmology 1985; 92:1305-10.

22 Safer JN, Gulbor P. Ocular complications of orbital venography. Radiology 1975;114:647-8.

23 Wilson ME, Parker PL, Chavis RM. Conservative management of childhood orbital lymphangioma. Ophthalmology 1989;96:484-9.

24 Behrendt S, Bersmeier H, Randzio G. Fractionated beta-irradiation of a conjunctival lymphangioma. Ophthalmologica 1991;203:161-3.

25 Herbreteau D, Riche MC, Enjolras O, et al. Percutaneous embolization with Ethibloc of lymphatic cystic malformations with a review of the experience in 70 patients. Int Angiol 1993;12:34-9. 